2018-12

\title{
Compressive stress-strain relation of recycled aggregate concrete under cyclic loading
}

$\mathrm{Hu}, \mathrm{X}$

http://hdl.handle.net/10026.1/12722

10.1016/j.conbuildmat.2018.10.137

Construction and Building Materials

Elsevier

All content in PEARL is protected by copyright law. Author manuscripts are made available in accordance with publisher policies. Please cite only the published version using the details provided on the item record or document. In the absence of an open licence (e.g. Creative Commons), permissions for further reuse of content should be sought from the publisher or author. 
This paper is published on:

Construction and Building Materials 193(2018): 72-83.

\title{
Compressive stress-strain relation of recycled aggregate concrete under cyclic loading
}

\author{
Xiaobin $\mathrm{Hu}^{1}$, Qinwang $\mathrm{Lu}^{1}$, Zihao $\mathrm{Xu}^{1}$, Wenliang Zhang ${ }^{1}$, Shanshan Cheng ${ }^{2 *}$ \\ 1. School of Civil Engineering, Wuhan University, Wuhan 430072, China \\ 2. School of Engineering, University of Plymouth, UK. PL4 8AA
}

\begin{abstract}
This paper has focused on the structural performance of recycled aggregate concrete (RAC) under both cyclic and monotonic loading. RAC specimens with different recycled coarse aggregate (RCA) replacement percentages of $0 \%, 25 \%, 50 \%, 75 \%$ and $100 \%$ were cast and tested. The compressive stress-strain relationship and the failure mode were investigated for each RCA replacement ratio. The effects of the RCA replacement percentage on the compressive mechanical properties of the RAC specimens including the strength, elastic modulus, peak strain, ultimate strain and Poisson's ratio were also studied. The RAC specimens have shown similar failure characteristics regardless of monotonic or cyclic loading. In addition, the compression skeleton curves of the RAC specimens under cyclic loading agree well with those under monotonic loading. Based on the experimental results, the characteristic points pertaining to the hysteresis loop were defined and their relations were established. Furthermore, the constitutive equations of the RAC as well as its simplified form were proposed and applied in numerical simulations of RAC columns and frames under cyclic loading. The proposed constitutive equations have shown promising accuracy in predicting the hysteresis performance of RAC on both component and structural levels.
\end{abstract}

Keywords: recycled aggregate concrete; replacement percentage; cyclic loading; stress-strain relation; constitutive equation

\footnotetext{
* to whom correspondence should be addressed

Tel:+44 (0)1752586112; Fax:+44 (0)1752586100;E-mail: shanshan.cheng@plymouth.ac.uk
} 


\section{Introduction}

Along with rapid urbanization, a large amount of waste concrete has been generated due to the renovation or demolition of existing buildings. The waste concrete is usually abandoned in suburb areas, which occupies a lot of land and may heavily jeopardize the surrounding environment. The recycled aggregate concrete (RAC) technology has been recognized as an effective way to reuse the waste concrete [1]. The RAC is mainly composed of recycled coarse aggregate (RCA) and/or natural coarse aggregate (NCA), natural fine aggregate, water and cement binder. Compared to the natural coarse aggregate, the recycled coarse aggregate often has larger porosity, water absorption and may possess inner damage due to crushing processing of the waste concrete. Moreover, its surface is usually surrounded by the old mortar [2]. Therefore, the RAC may perform rather differently comparing to the normal concrete (NC).

The compressive mechanical properties of the RAC are crucial in structural design and analysis of the RAC components or structures, and have thus attracted much attention in recent decades. A number of researchers (e.g. Topçu et al. [3], Xiao et al. [4], Deng et al. [5], Akbarnezhad et al. [6] and Martinez-Lage et al. [7]) have experimentally investigated the mechanical properties of RAC specimens considering different RCA replacement percentages, and found that increasing the RCA replacement percentage will decrease the compressive strength and the elastic modulus of the RAC. In addition, Belén [8] stated that increasing the RCA replacement percentage results in the decrease of the Poisson's ratio but the increase of the peak and ultimate strain. On the contrary, Li [9] and Zhou et al [10] concluded that the Poisson's ratio of the RAC is close to or even higher than that of the NC. In addition to the above-mentioned studies, similar research works have been reported in references [11-14].

The above work reveals that in general the RCA has adverse effect on the mechanical properties of the RAC, e.g., reducing the strength and increasing the deformation. However, some researchers have drawn different conclusions. Laserna et al. [15] and Wang et al. [16] came to a conclusion that the RAC strength does not drop monotonously as the RCA replacement percentage increases. Rühl et al. [17] found that the RCA replacement percentage has little impact on the compressive strength. Etxeberria et al. [18], Manzi et al. [19], Deng et al. [20], Ho et al. [21], Salesa et al. [22] and Zhou et 
al. [10] even concluded that the compressive strength of RAC is similar or even higher than that of the NC. This phenomenon may be attributed to the higher water absorption of the RAC compared to the $\mathrm{NC}$, which decreases the effective water-cement ratio of the concrete mixture and thus improve the interfacial bond between the aggregates and cement $[10,18]$.

Apart from the compressive strength, the compressive stress-strain curves of the RAC have also been investigated. Bairagi and Kishore [23] conducted uniaxial compressive test of the RAC specimens to investigate the stress-strain relationship, and found that the curvature of the stress-strain curve gradually increases with the increase of the RCA replacement percentage, which results in decreased Young's modulus. Xiao et al. [4], Li [9], Deng et al. [20], and Wang et al. [16] conducted similar experimental investigations on the complete stress-strain curves of the RAC, and concluded that the slope of the descending branch of the RAC stress-strain curve decreases as the RCA replacement percentage increases, indicating a significant decrease in the ductility of the concrete. Other similar works can be seen in references [24-27].

Although considerable amount of researches have been conducted in investigating the mechanical properties of RAC, there is still no consensus about the impact of the RCA on the RAC. Moreover, the previous work mainly focused on the strength or deformation characteristics of the RAC under monotonic loading, whereas little attention has been paid to its behavior under cyclic loading. Therefore, this paper is to present the experimental work the authors have conducted on the mechanical behavior of the RAC under cyclic compressive loading. Based on the test results, the constitutive equations of the RAC are proposed and then applied to the numerical analyses of the RAC structures subjected to cyclic loading.

\section{Experimental program}

\subsection{Materials}

Ordinary Portland cement with a 28d compressive strength of $32.5 \mathrm{MPa}$ was used in this study. The fine aggregates used were river sand. The coarse aggregates included the NCA and RCA, the latter of which were obtained by crushing the waste concrete specimens. According to reference [28], the physical properties of the coarse aggregates were measured and shown in Table 1. It can be seen that the bulk density and the apparent density of the RCA are considerably lower than that of the NCA while its water absorption is substantially higher, which can be attributed to the existence of the old mortar adhered around the RCA. In addition, the RCA has a much larger crush index than that of the 
NCA, which can be explained by that the RCA has a rougher surface with more sharp corners caused by the crushing. Fig. 1 displays the grading curves of the NCA and RCA used in the test, as well as the lower and upper bound specified in reference [28], showing that both of them are continuously graded and meet the code requirement.

Table 1 Physical properties of the coarse aggregates

\begin{tabular}{cccccc}
\hline Type & $\begin{array}{c}\text { Grading } \\
(\mathrm{mm})\end{array}$ & $\begin{array}{c}\text { Bulk density } \\
\left(\mathrm{kg} / \mathrm{m}^{-3}\right)\end{array}$ & $\begin{array}{c}\text { Apparent } \\
\text { density }\left(\mathrm{kg} / \mathrm{m}^{-3}\right)\end{array}$ & $\begin{array}{c}\text { Water } \\
\text { absorption }(\%)\end{array}$ & $\begin{array}{c}\text { Crush index } \\
(\%)\end{array}$ \\
\hline NCA & $5 \sim 31.5$ & 1423 & 2810 & 0.56 & 6.7 \\
RCA & $5 \sim 31.5$ & 1281 & 2506 & 4.2 & 15.5 \\
\hline
\end{tabular}

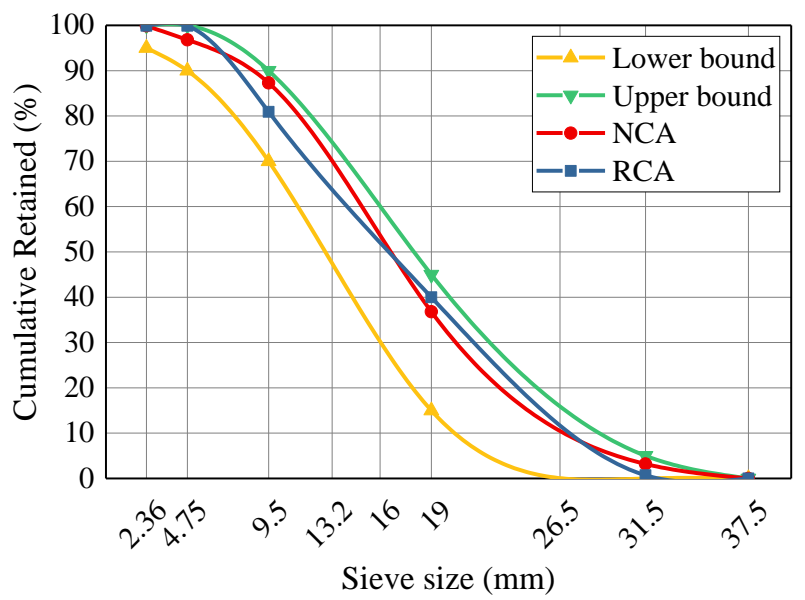

Fig. 1 Grading curves of the coarse aggregates used in the test

\subsection{Preparation of specimens}

A total of five groups of RAC specimens were taken into account, considering five different replacement percentages of the RCA, which are $0 \%, 25 \%, 50 \%, 75 \%$ and $100 \%$ respectively. In the case of $0 \%$ RCA replacement, the RAC turns to NC and serves as the reference concrete. Each group consists of six prism specimens with the size of $150 \mathrm{~mm} \times 150 \mathrm{~mm} \times 300 \mathrm{~mm}$ and three cube specimens with the size of $150 \mathrm{~mm} \times 150 \mathrm{~mm} \times 150 \mathrm{~mm}$ [29]. Among the six prism specimens, three were tested under cyclic compressive loading while the rest were tested under monotonic compressive loading. The cube specimens were used to obtain the cubic compressive strength of the RAC.

The mix proportion of the RAC for the specimens is determined according to reference [1]. For all specimens, the water/cement (w/c) ratio was kept constant as 0.43 . The mix proportions of the $\mathrm{RAC}$ are listed in Table 2, where the number in the first column denotes the RCA replacement percentage. It is worth noting that the additional water is considered to account for the high water 
absorption of the RCA. All mixing of the specimens was conducted under laboratory conditions and cured for 28 days.

Table 2 Mix proportions of the RAC

\begin{tabular}{cccccccc}
\hline No. & $\begin{array}{c}\text { RCA replacement } \\
\text { percentage (\%) }\end{array}$ & $\begin{array}{c}\text { Cement } \\
\left(\mathrm{kg} / \mathrm{m}^{3}\right)\end{array}$ & $\begin{array}{c}\text { Sand } \\
\left(\mathrm{kg} / \mathrm{m}^{3}\right)\end{array}$ & $\begin{array}{c}\text { NCA } \\
\left(\mathrm{kg} / \mathrm{m}^{3}\right)\end{array}$ & $\begin{array}{c}\text { RCA } \\
\left(\mathrm{kg} / \mathrm{m}^{3}\right)\end{array}$ & $\begin{array}{c}\text { Water } \\
\left(\mathrm{kg} / \mathrm{m}^{3}\right)\end{array}$ & $\begin{array}{c}\text { Additional } \\
\text { water } \\
\left(\mathrm{kg} / \mathrm{m}^{3}\right)\end{array}$ \\
\hline NC & 0 & 430 & 618 & 1200 & 0 & 185 & 0 \\
RAC-25 & 25 & 430 & 607 & 883 & 295 & 185 & 12.4 \\
RAC-50 & 50 & 430 & 595 & 578 & 578 & 185 & 24.3 \\
RAC-75 & 75 & 430 & 585 & 284 & 851 & 185 & 35.7 \\
RAC-100 & 100 & 430 & 574 & 0 & 1114 & 185 & 46.8 \\
\hline
\end{tabular}

\subsection{Test setup and method}

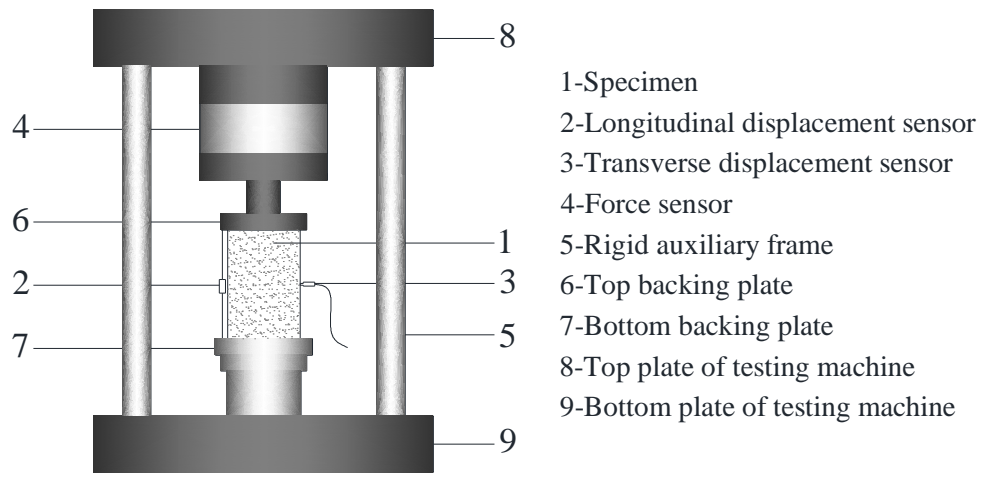

(a) Schematic diagram

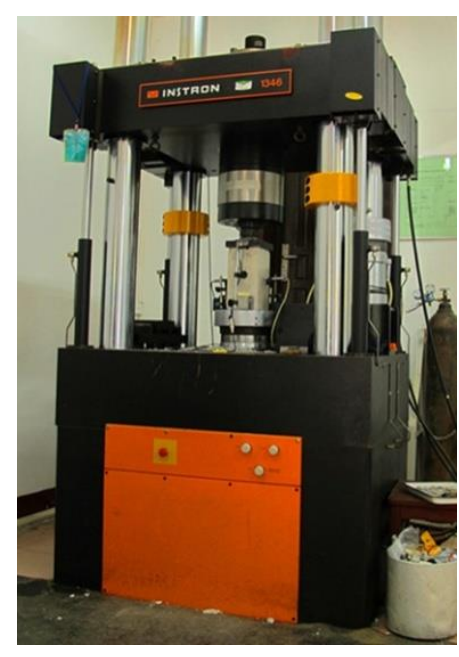

(b) Test photo

Fig. 2 Test setup

All the prism specimens were tested using the INSTRON electro-hydraulic servo test machine as shown in Fig. 2. The axial force acted on the specimen was obtained by the force transducer, and the longitudinal and transverse displacements were measured using the displacement sensor. For the monotonic test, the displacement loading rate was kept as $0.02 \mathrm{~mm} / \mathrm{s}$, corresponding to a strain rate of $67 \times 10^{-6} / \mathrm{s}$. For the cyclic test, the load was applied for a number of cycles up to the failure of specimens, and the maximum strain at each cycle increases by about $1 \times 10^{-3}$. For each cycle, the specimen was first loaded with the strain rate of $67 \times 10^{-6} / \mathrm{s}$ and then unloaded at the rate of $10 \mathrm{kN} / \mathrm{s}$ until zero. 


\section{Test results}

\subsection{Failure characteristics}

For the monotonic test, there was no visible crack on the specimen surface in the early stage of loading. With the increase of loading, longitudinal micro-cracks appeared on the specimen surface, and then gradually developed into inclined cracks. After reaching the peak stress, the inclined cracks increasingly developed longer and wider until the specimen was ultimately crushed. For the cyclic test, similar failure modes were observed, except that under a loading cycle, the cracks opened under loading and then closed gradually when unloading, as shown in Fig. 3. However, the cracks did not close completely when unloaded due to the interlocking effect of coarse aggregates.

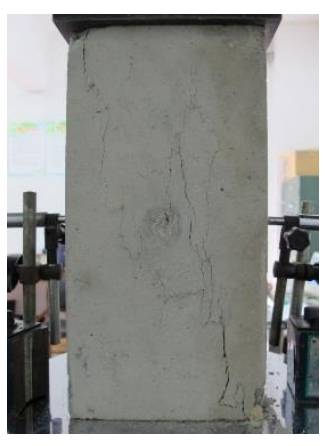

(a) Loading

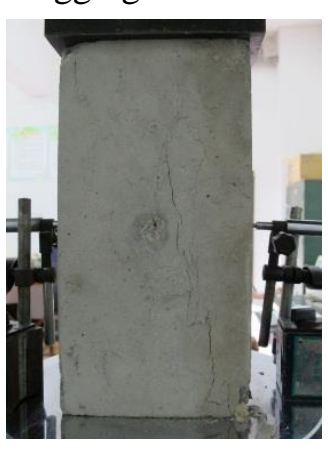

(b) Unloading

Fig. 3 The observation of the RAC specimen under cyclic loading

The failure characteristics of the RAC and NC specimens under monotonic or cyclic loading were found to be similar, i.e., they were all ultimately crushed with diagonal fractures on the surface. However, as seen in Fig. 4, small inclined cracks were widely developed only on the surface of the RAC specimens; on the contrast, one main inclined crack appeared on the surface of the NC specimen. In addition, the inclination angle of the main crack on the surface of the RAC specimen with respect to the longitudinal axis was generally larger than that of the NC specimen.

The above phenomena can be explained by looking into the mesoscopic structure of the concrete. As is well known, concrete consists of three components: coarse aggregate, hardened cement paste and interfacial transition zone (ITZ) between the former two parts. The ITZs is usually the weakest region in the concrete and the cracks always develop along the ITZs [30]. Different from the NC, the RAC possesses two types of ITZs including original ITZs between the NCA and adhered mortar and new ITZs between the RCA and the mortar. Compared to the original ITZs, the new ITZs is more susceptible to fragmentation [31]. Therefore, more secondary cracks develop on the surface of the 
RAC. Moreover, the ITZs weaken the aggregate interlock capacity of the RAC, which leads to larger inclination angle of the main crack on the surface of the RAC.

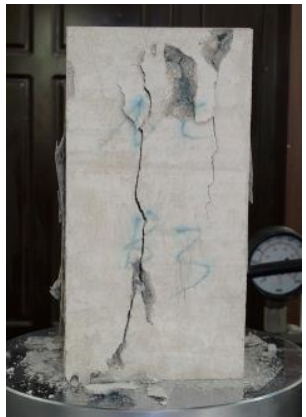

(a) $\mathrm{NC}$

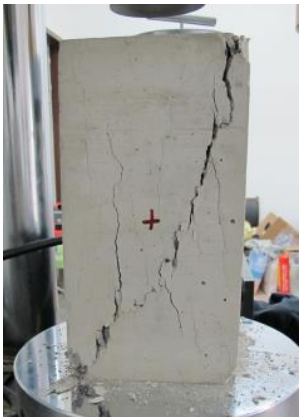

(b) RAC-25

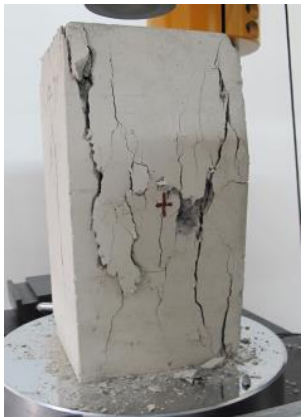

(c) RAC-50

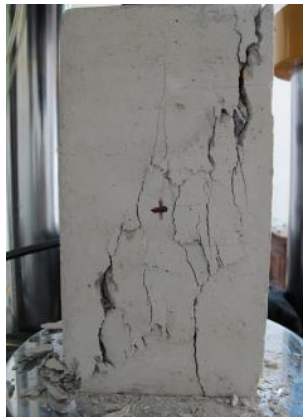

(d) RAC-75

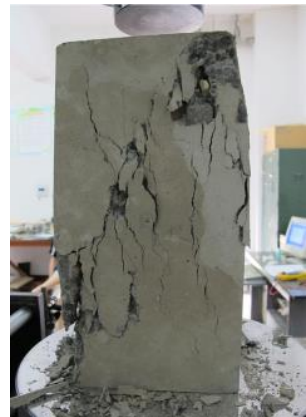

(e) RAC-100

Fig. 4 Failure patterns of the RAC specimens

\subsection{Stress-strain curves}

Based on the tests, the axial force vs. displacement curves of the RAC specimens were obtained and can be converted into the stress-strain curves by

$$
\sigma^{\mathrm{r}}=N / A, \quad \varepsilon^{\mathrm{r}}=\Delta l / l
$$

where, $\varepsilon^{\mathrm{r}}$ and $\sigma^{\mathrm{r}}$ are the strain and stress of the RAC respectively; $N$ and $\Delta l$ represent the axial force and displacement respectively; $A$ and $l$ are the cross-sectional area and length of the specimen.

Fig. 5 shows the stress-strain curves of the RAC specimens under both monotonic and cyclic loading. Each curve was obtained by averaging the test results from the three specimens. Based on the stress-strain curves corresponding to cyclic loading, the skeleton curves can be drawn by connecting the peak points of all cycles, which are also shown in Fig. 5. It can be seen that in general the skeleton curve agrees well with the curve pertaining to monotonic loading irrespective of the RCA replacement percentage.
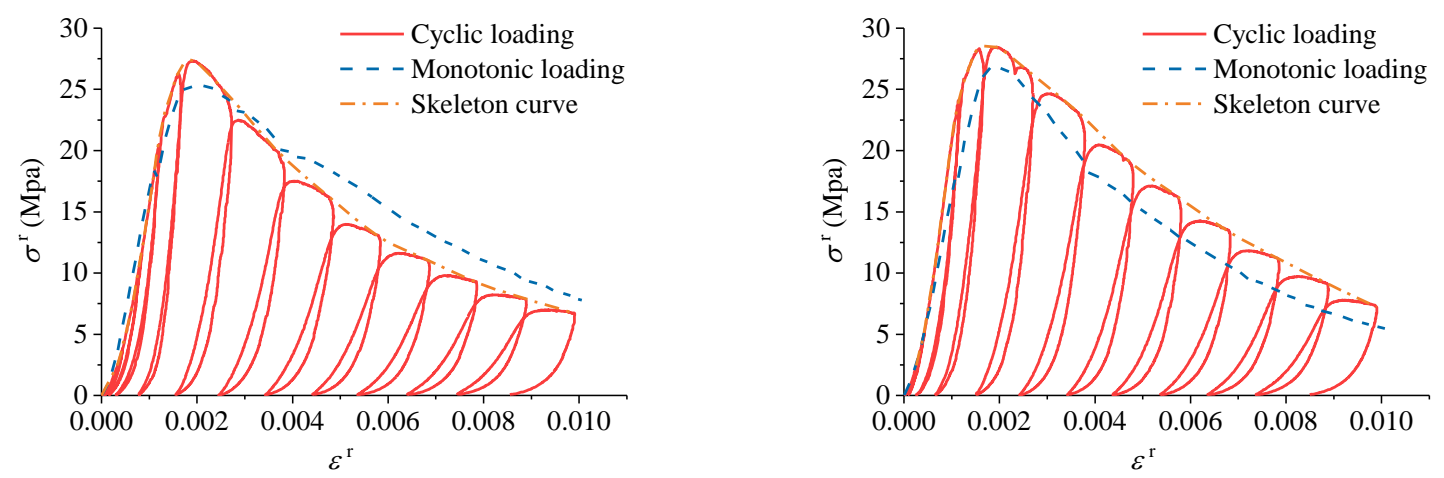
(a) $\mathrm{NC}$

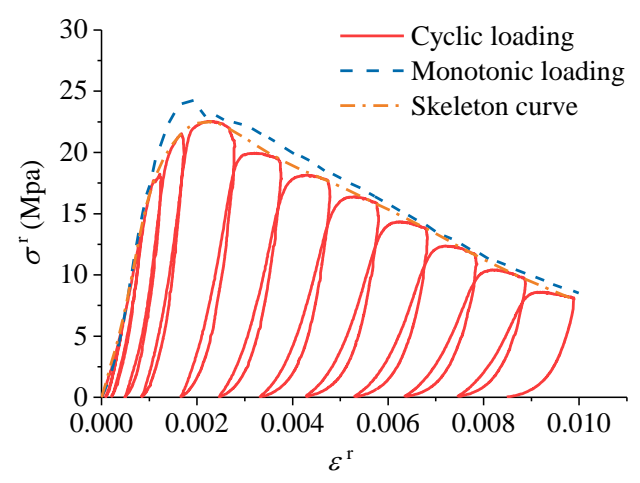

(c) RAC-50 (b) RAC-25

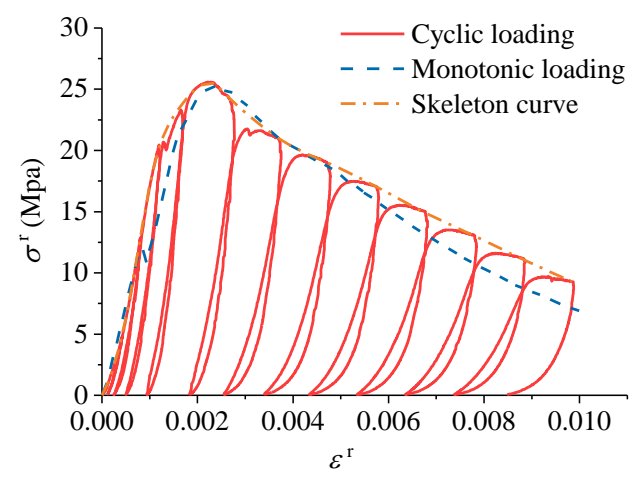

(d) RAC-75

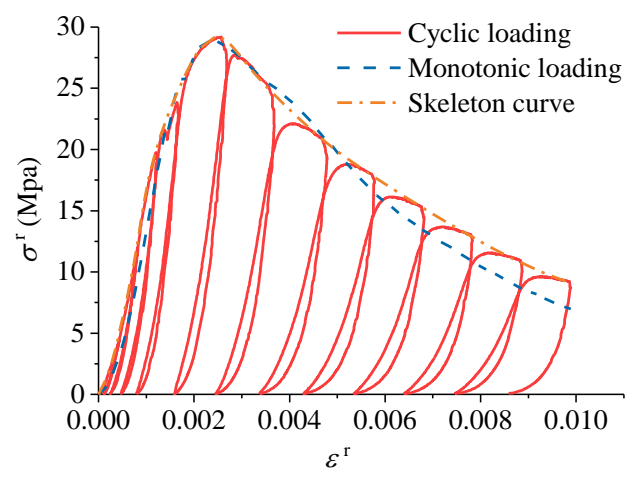

(e) RAC-100

Fig. 5 Stress-strain curves of the RAC specimens

In addition, it is worth noting that for each hysteresis loop under cyclic loading the average slope of both the unloading and reloading branches decreases with the increase of the maximum strain. It can be attributed to the development of damage resulted from the growth of internal micro-cracks in the specimens.

\subsection{Effect of the RCA replacement percentage}

The skeleton curves of the RAC specimens under cyclic loading for different replacement percentage of the RCA are plotted in Fig. 6. It can be seen that all curves are nearly consistent when the stress is smaller than $16 \mathrm{MPa}$, indicating that the RCA replacement percentage has little effect on the ascending branch of the skeleton curves, in particular in the elastic range. However, after elastic range, obvious difference can be observed among these curves in terms of the peak stress and the slope of the descending branch. It exhibits no consistent relation between the RCA replacement percentage and the peak stress or the slope of the descending branch. However, similar to the NC, the 
slope of the descending branch of the RAC decreases as the peak stress increases, implying larger post-peak deformation at the same stress level.

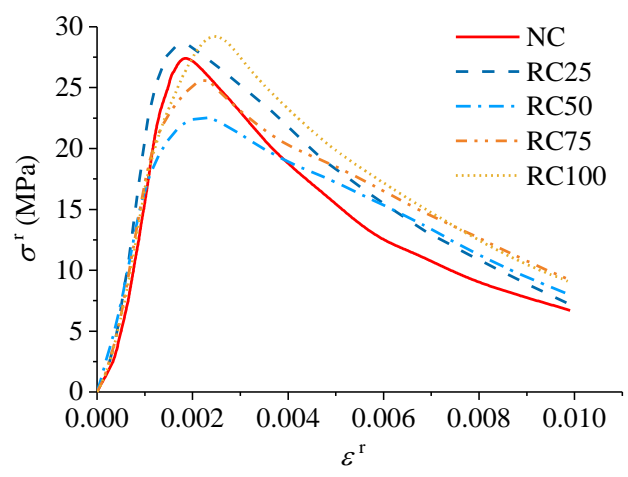

Fig. 6 Effect of the RCA replacement percentage on the skeleton curves

Based on the skeleton curves of the RAC specimens under cyclic loading, the strength and deformation properties of the RAC specimens can be extracted. Fig. 7 displays the prism strength corresponding to different RCA replacement percentages as well as the cube strength, where $r$ represents the RCA replacement percentage. It can be seen that both the prism and the cube strength exhibit similar variance tendency as the RCA replacement percentage increases, except for that the replacement percentage seems to have larger influence on the prism strength compared to the cube strength. Moreover, it can be found that when the RCA replacement percentage is less than $50 \%$, the compressive strength decreases with the increase of the RCA replacement. However, when the RCA replacement percentage is higher than $50 \%$, the compressive strength increases with the increase of the RCA replacement percentage. It shows no monotonous relation between the strength and the RCA replacement percentage, which was also reported in reference [16]. It may be attributed to the experimental randomness or the complex interaction mechanism between the RCA and NCA, which needs to be further investigated on the mesoscopic level by numerical analysis or experiments in the future study. 


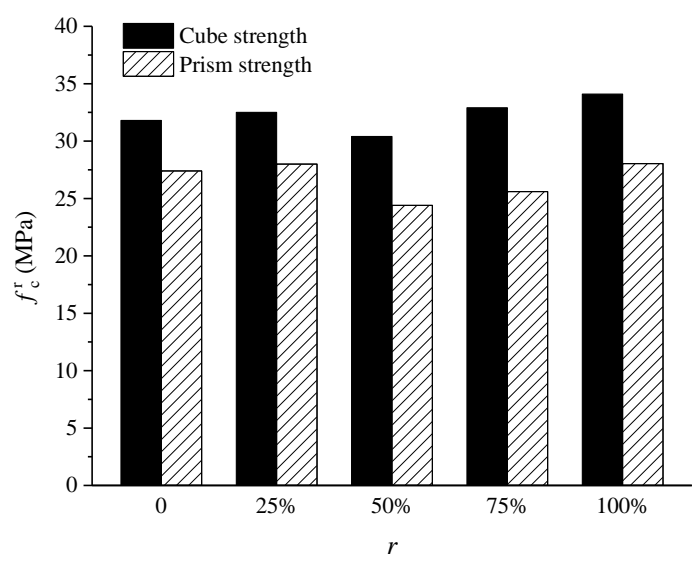

Fig. 7 Effect of the RCA replacement percentage on the RAC strength

Fig. 8 presents the effect of the RCA replacement percentage on the deformation properties including peak strain $\varepsilon_{0}^{\mathrm{r}}$ corresponding to the peak stress $f_{\mathrm{c}}^{\mathrm{r}}$, maximum strain $\varepsilon_{\mathrm{u}}^{\mathrm{r}}$, elastic modulus $E^{\mathrm{r}}$ and Poisson's ratio $v^{\mathrm{r}}$. The maximum strain is defined as the strain corresponding to $50 \%$ of the peak stress in the descending branch. The elastic modulus is calculated directly from the stress vs. strain curve according to

$$
E^{r}=\frac{\sigma_{2}-\sigma_{1}}{\varepsilon_{2}-0.005 \%}
$$

where $\sigma_{1}$ is the stress corresponding to a strain of $0.005 \%, \sigma_{2}$ is the stress corresponding to $40 \%$ of the peak stress, and $\varepsilon_{2}$ is the strain at the stress level $\sigma_{2}$ [4].

Fig. 8 indicates that, unlike the strength, the deformation properties in terms of peak strain and Poisson's ratio have consistent relationship with the RCA replacement percentage. Increasing the RCA replacement percentage will generally increase the peak strain but decrease the Poisson's ratio. However, similar to the strength, the maximum strain and elastic modulus fluctuates with the increase of the RCA replacement ratio, which agree with the findings of Xiao et al. [4]. 


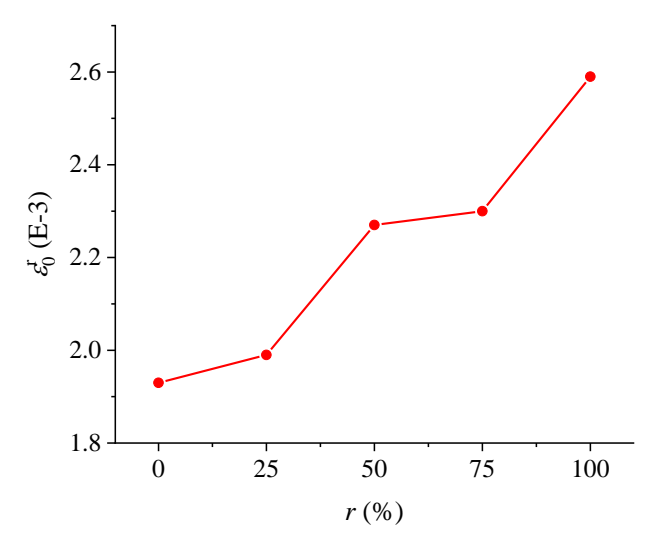

(a) Peak strain

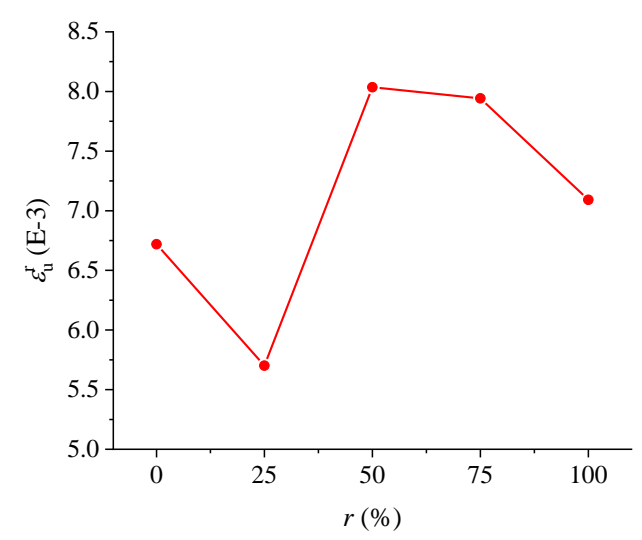

(c) Maximum strain

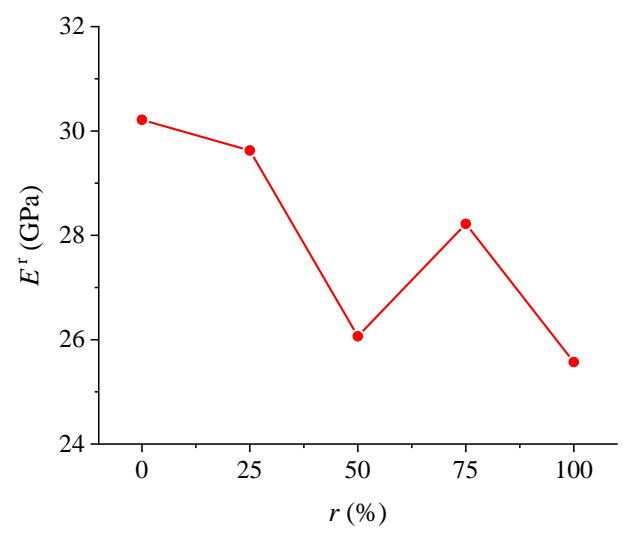

(b) Elastic modulus

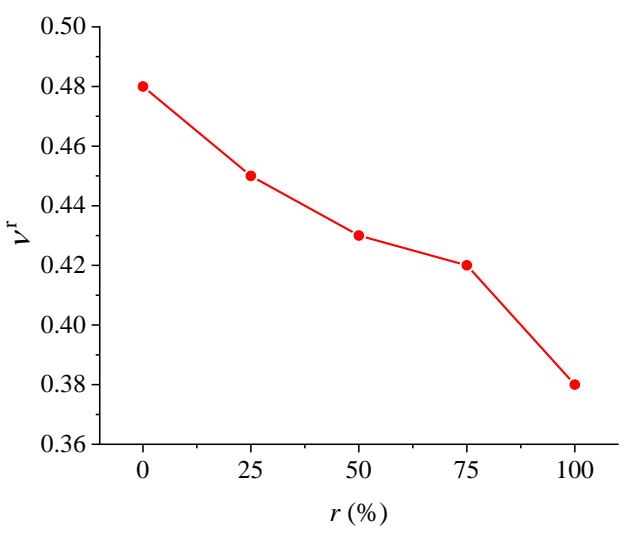

(d) Poisson's ratio

Fig. 8 Effect of the RCA replacement percentage on the RAC deformation properties

\section{Constitutive relations under cyclic loading}

\subsection{Typical hysteresis curves}

To facilitate the establishment of the constitutive equations of the RAC under cyclic loading, the dimensionless stress-strain curves of the RAC specimens, as shown in Fig. 9, are obtained by

$$
x=\varepsilon^{\mathrm{r}} / \varepsilon_{0}^{\mathrm{r}}, \quad y=\sigma^{\mathrm{r}} / f_{\mathrm{c}}^{\mathrm{r}}
$$

In the following sections, the stress and strain of the RAC are both in the dimensionless form unless otherwise specified. 


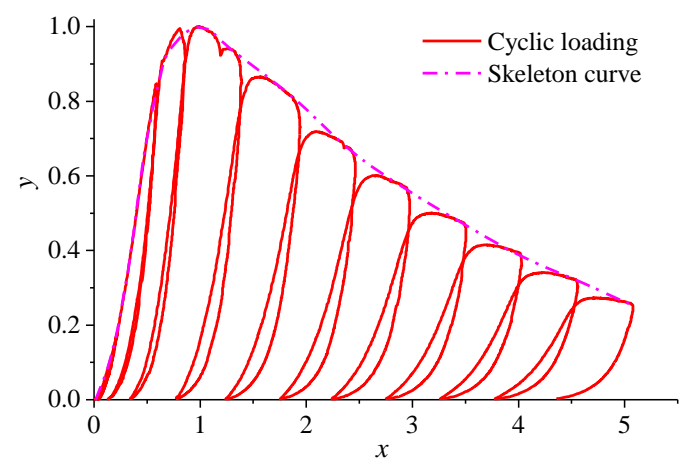

Fig. 9 Dimensionless stress-strain curves of the RAC specimens

The typical hysteresis loop of the RAC specimens under cyclic loading comprises the unloading curve and reloading curve. A total of four characteristic points can be defined on the loop as shown in Fig. 10, i.e., unloading point, residual point, common point where the unloading curve intersects the reloading curve, and end point where the reloading curve intersects the skeleton curve,. In Fig. 10, $x_{\mathrm{u}}$ and $y_{\mathrm{u}}$ are the strain and stress of the unloading point respectively, $x_{\mathrm{r}}$ is the strain of the residual point, $x_{\mathrm{c}}$ and $y_{\mathrm{c}}$ are the strain and stress of the common point respectively, and $x_{\mathrm{e}}$ and $y_{\mathrm{e}}$ are the strain and stress of the end point.

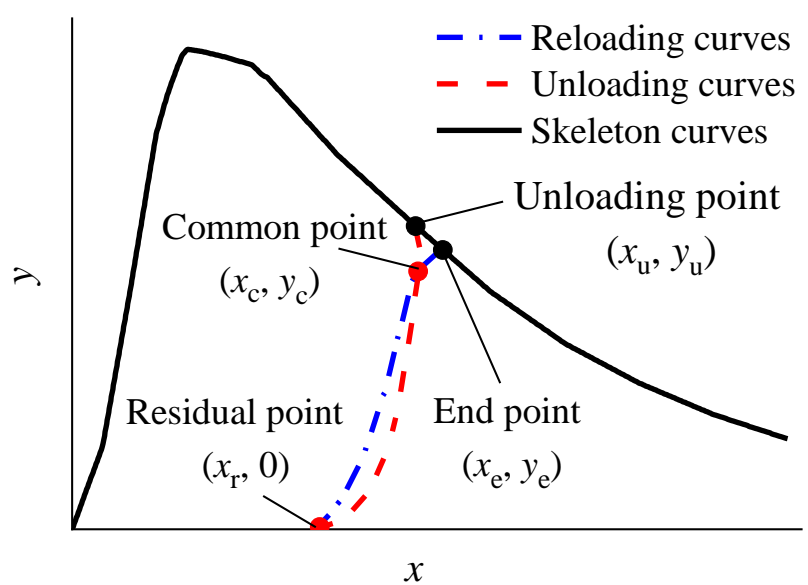

Fig. 10 Typical hysteresis loop of the RAC specimens under cyclic loading

\subsubsection{Residual point}

As observed in Fig. 10, when unloading occurs before the peak point, i.e., $x_{\mathrm{u}}<1$, the unloading curve is approximately linear and intersects the horizontal axis with small residual strain. However, for $x_{\mathrm{u}}>1$, as $x_{\mathrm{u}}$ increases, both the $x_{\mathrm{r}}$ and the curvature of the unloading curve will increase.

Assuming that $x_{\mathrm{r}}$ and $x_{\mathrm{u}}$ can be approximated by the following equation: 


$$
x_{\mathrm{r}}=a x_{\mathrm{u}}^{b}
$$

where $a$ and $b$ are both parameters to be determined. Based on the experimental results, the values of $a$ and $b$ (listed in Table 3) were obtained by regression. It can be seen that both $a$ and $b$ vary little with the change of the RCA replacement percentage $r$, therefore the average values are employed, i.e., $a=$ $0.54, b=1.31$.

Table 3 Values of $a$ and $b$ for different replacement percentages

\begin{tabular}{cccccc}
\hline$r(\%)$ & 0 & 25 & 50 & 75 & 100 \\
\hline$a$ & 0.52 & 0.52 & 0.54 & 0.56 & 0.57 \\
$b$ & 1.30 & 1.31 & 1.31 & 1.31 & 1.32 \\
\hline
\end{tabular}

\subsubsection{Common point}

The common point is defined as the intersection between the unloading curve and the reloading curve. As seen in Fig. 10, the strain of common point $x_{\mathrm{c}}$ increases with the increase of the unloading strain $x_{\mathrm{u}}$. It is assumed that $x_{\mathrm{c}}$ and $x_{\mathrm{u}}$ have the following linear relationship:

$$
x_{\mathrm{c}}=c x_{\mathrm{u}}+d
$$

where $c$ and $d$ are both parameters to be determined. Table 4 has listed the values of $c$ and $d$ obtained using regression analysis on the experimental data. Again, an average value of 0.997 has been adopted for $c$ due to its little variation with the increase of $r$.

Table 4 Values of $c$ and $d$ for different replacement percentages

\begin{tabular}{cccccc}
\hline$r(\%)$ & 0 & 25 & 50 & 75 & 100 \\
\hline$c$ & 0.993 & 0.995 & 0.997 & 1.000 & 1.002 \\
$d$ & -0.017 & -0.022 & -0.030 & -0.035 & -0.041 \\
\hline
\end{tabular}

\subsubsection{End point}

As shown in Fig. 10, while increasing the unloading strain $x_{\mathrm{u}}$, the end point has demonstrated similar trend as the residual point. Assuming $x_{\mathrm{e}}$ and $x_{\mathrm{u}}$ meet the following relationship:

$$
x_{\mathrm{e}}=m x_{\mathrm{u}}^{n}
$$

where $m$ and $n$ are both parameters to be determined using regression analysis of the experimental data (shown in Table 5). 
Table 5 Values of $m$ and $n$ for different replacement percentages

\begin{tabular}{cccccc}
\hline$r(\%)$ & 0 & 25 & 50 & 75 & 100 \\
\hline$m$ & 1.132 & 1.110 & 1.137 & 1.125 & 1.106 \\
$n$ & 0.943 & 0.951 & 0.939 & 0.949 & 0.960 \\
\hline
\end{tabular}

\subsection{Skeleton curves}

As shown in Fig. 5, RAC specimens have demonstrated similar shapes of skeleton curves under cyclic loading compared to the stress-strain curves under monotonic loading. Therefore, the analytical model of the stress-strain relationship of the RAC under monotonic loading, initially proposed by Guo [32] and later extended by Xiao et al. [4], is adopted in this study to describe the skeleton curve of the RAC under cyclic loading:

$$
y=\left\{\begin{array}{lc}
p x+(3-2 p) x^{2}+(p-2) x^{3}, & 0 \leq x<1 \\
x /\left[q(x-1)^{2}+x\right], & x \geq 1
\end{array}\right.
$$

where $p$ and $q$ are parameters to be determined using experimental method. Based on the experimental data obtained in this study, the relationship among $p, q$ and $r$ can be established as follows:

$$
\begin{gathered}
p=-3.39 r^{2}+4.26 r+0.26 \\
q=1.54 r^{2}-1.48 r+0.88
\end{gathered}
$$

\subsection{Unloading curves}

According to the characteristics of the unloading curves obtained through experiments, it is assumed that the unloading curve follows the analytical expression given in Eq. (9):

$$
\frac{y}{y_{\mathrm{u}}}=m_{\mathrm{u}}\left(\frac{x-x_{\mathrm{r}}}{x_{\mathrm{u}}-x_{\mathrm{r}}}\right)^{n_{\mathrm{u}}}
$$

where $m_{\mathrm{u}}$ and $n_{\mathrm{u}}$ are determined using the experimental data obtained in this research:

$$
\begin{gathered}
m_{\mathrm{u}}=1.0 \\
n_{\mathrm{u}}=3.11 \sqrt{x_{\mathrm{r}}}-1.11 x_{\mathrm{r}}+0.925
\end{gathered}
$$

where $x_{\mathrm{r}}$ is the residual strain.

\subsection{Reloading curves}

As shown in Fig. 10, a reloading curve can be divided into two branches, one connecting the 
residual point to the common point and the other connecting the common point to the end point. It is assumed that the first branch follows a power function and the second is linear:

$$
\begin{gathered}
y=y_{\mathrm{c}} m_{\mathrm{r}}\left(\frac{x-x_{\mathrm{r}}}{x_{\mathrm{c}}-x_{\mathrm{r}}}\right)^{n_{\mathrm{r}}}, x<x_{\mathrm{c}} \\
y=\frac{y_{\mathrm{e}}-y_{\mathrm{c}}}{x_{\mathrm{e}}-x_{\mathrm{c}}}\left(x-x_{\mathrm{c}}\right)+y_{\mathrm{c}}, x \geq x_{\mathrm{c}}
\end{gathered}
$$

where $m_{\mathrm{r}}=1.0$ and $n_{\mathrm{r}}=1.52$ were determined using the experimental data.

It is worth noting that Eq. (11) is only applicable to the cases of complete unloading, i.e., the stress is unloaded to zero. For partial unloading (as shown in Fig. 11), a similar analytical expression may be used alternatively as follows:

$$
\begin{gathered}
y=y_{\mathrm{c}} m_{\mathrm{pr}}\left(\frac{x-x_{\mathrm{pr}}}{x_{\mathrm{c}}-x_{\mathrm{pr}}}\right)^{n_{\mathrm{pr}}}+y_{\mathrm{pr}}, x<x_{\mathrm{c}} \\
y=\frac{y_{\mathrm{e}}-y_{\mathrm{c}}}{x_{\mathrm{e}}-x_{\mathrm{c}}}\left(x-x_{\mathrm{c}}\right)+y_{\mathrm{c}}, x \geq x_{\mathrm{c}}
\end{gathered}
$$

where $m_{\mathrm{pr}}$ and $n_{\mathrm{pr}}$ are parameters to be determined using experimental methods; $x_{\mathrm{pr}}$ and $y_{\mathrm{pr}}$ are the strain and stress corresponding to the point where the partial unloading ends.

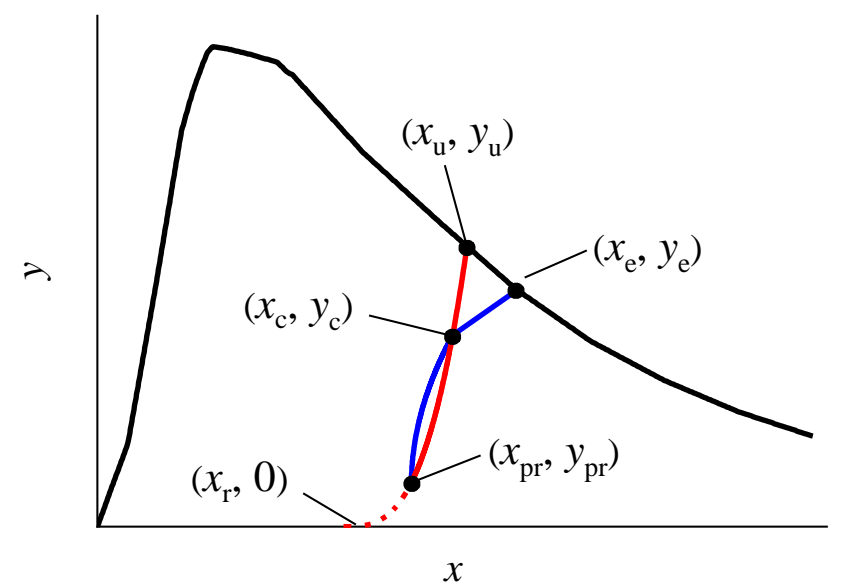

Fig. 11 Hysteresis curve in case of partial unloading

\subsection{Verifications of the constitutive equations}

Eqs. (4) - (11) form the complete constitutive model of the RAC under cyclic compressive loading, which takes into account the effect of the RCA replacement percentage. Therefore, the constitutive model could also be applied to the NC, by setting the RCA replacement percentage as 
zero. Using the proposed equations in this study, the stress-strain curves of the RAC specimens under cyclic loading were calculated and compared with the experimental results (as shown in Fig. 12). Overall the predicted curves agree well with the experimental data, indicating that the proposed constitutive equations could well capture the mechanical behavior of the RAC specimens under cyclic loading.

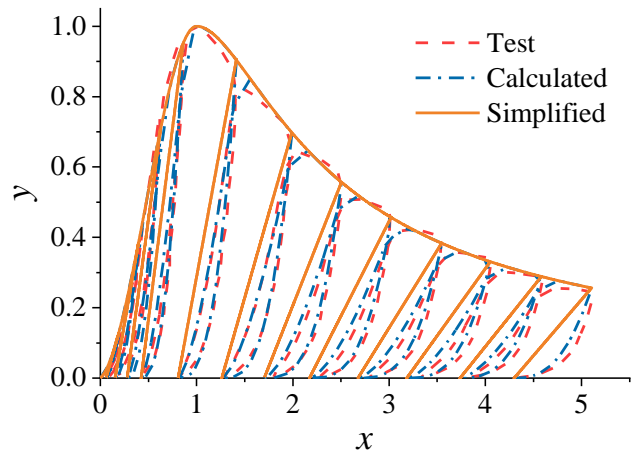

(a) $\mathrm{NC}$

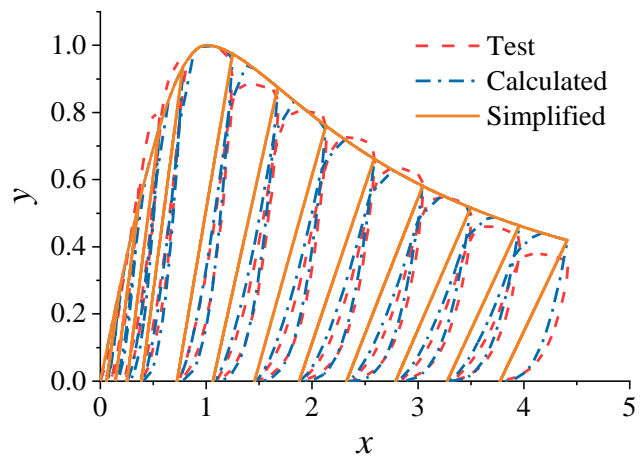

(c) $\mathrm{RC}-50$

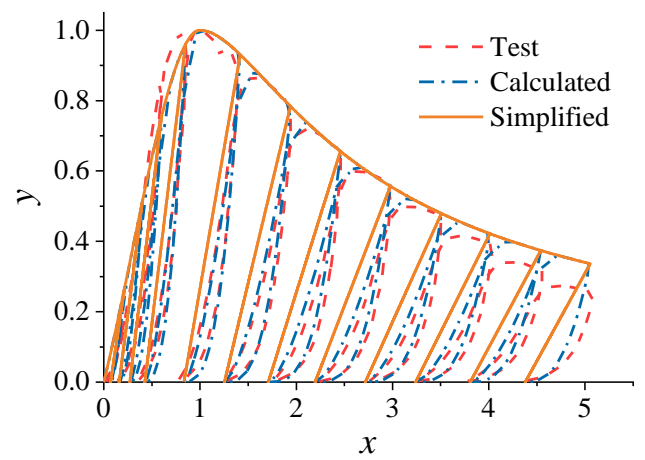

(b) RC-25

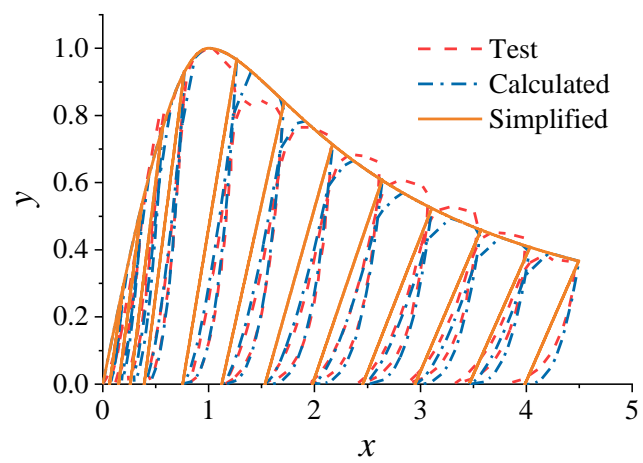

(d) RC-75

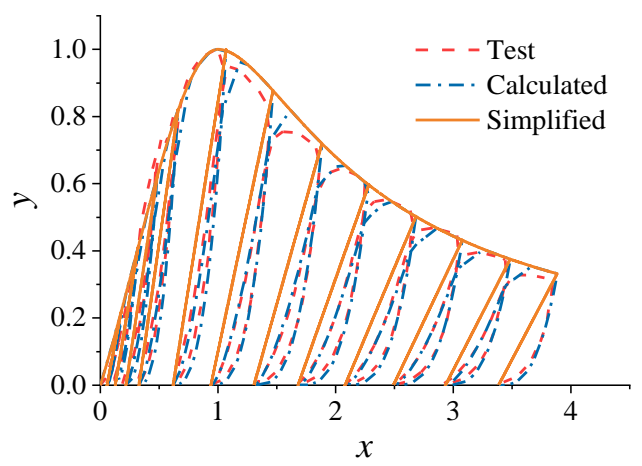

(e) RC-100

Fig. 12 Comparisons between the calculated stress-strain curves and experimental results 
The experimental results obtained by other researchers $[4,5,8]$ were also utilized to further validate the proposed constitutive equations. Fig. 13 compares the predicted and the experimental stress-strain curves of the RAC specimens with different RCA replacement ratios and under monotonic loading. Again, good agreement has been achieved.

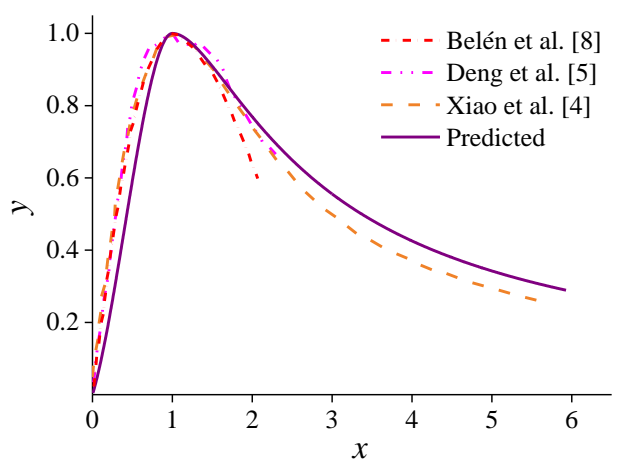

(a) $\mathrm{NC}$

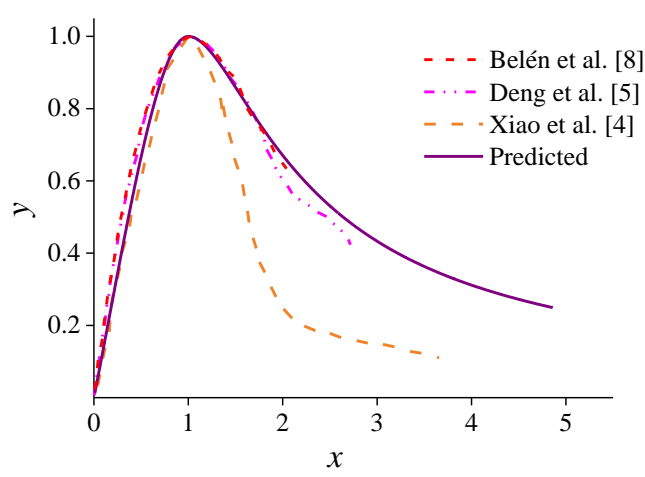

(b) RC-100

Fig. 13 Comparisons between the experimental results and predicted ones of RAC under monotonic loading

In addition, the complete constitutive equations proposed in this paper were also validated using the experimental stress-strain relationship of the NC under cyclic loading [33], as shown in Fig. 14. It can be seen that the predicted curve agrees well with the experimental one, indicating again that the proposed constitutive model under cyclic loading has a good accuracy.

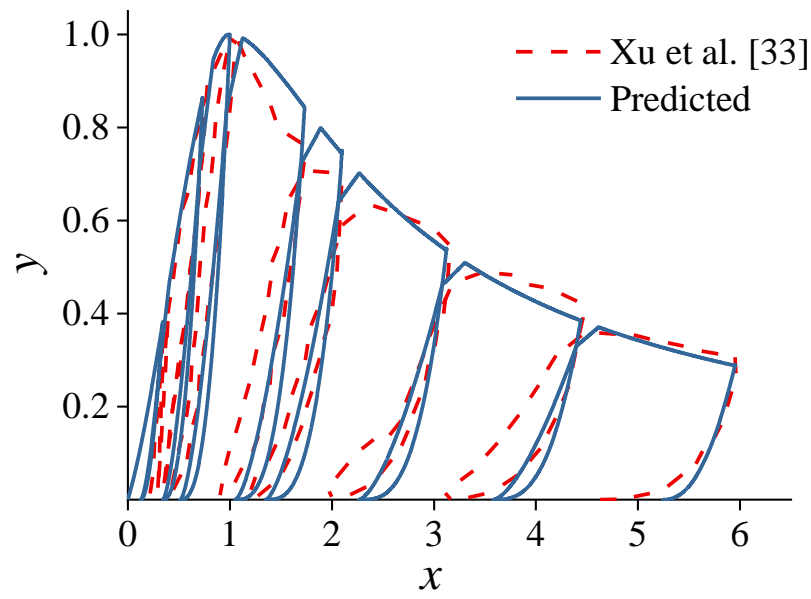

Fig. 14 Comparisons between the experimental results and predicted ones of NC under cyclic loading 


\subsection{Simplification of constitutive equations}

Although the constitutive equations have shown great accuracy, the equations of unloading and reloading curves, i.e., Eqs. (9) and (11), are relatively complex, which is not convenient for engineering applications. To address this issue, the unloading and reloading curves are simplified to be linear and coincide with each other:

$$
\frac{y}{y_{\mathrm{u}}}=\frac{x-x_{\mathrm{r}}}{x_{\mathrm{u}}-x_{\mathrm{r}}}
$$

Eqs. (7) and (13) along with Eq. (4) form the simplified constitutive equations of the RAC under cyclic compressive loading. Compared to the original form, the simplified constitutive equations have much less parameters and therefore higher efficiency especially in the nonlinear analysis of the RAC structures. Fig. 12 also shows the predicted stress-strain relationship of the RAC specimens under cyclic loading using the simplified constitutive equations. Satisfactory agreement has been achieved, indicating that the simplified constitutive equations can be potentially employed to describe the hysteresis behavior of the RAC under cyclic loading while benefiting from high computational efficiency.

\section{Applications of the proposed RAC constitutive model}

\subsection{Development of the UMAT subroutine}

In Section 3, the constitutive relation of RAC under cyclic loading and its simplified form were proposed and validated based on experimental results. It can be seen that the simplified form is more appealing in finite element analysis of RAC structures especially for complex structures. Therefore, the simplified constitutive model is chosen to develop the UMAT subroutine for the RAC material in ABAQUS [35]. The tensile behavior of the RAC is not taken into account and the tensile stress is set to be zero.

The flow diagram of the UMAT subroutine for the RAC material is shown in Fig. 15. It mainly includes the following steps: (1) initializing the state parameters. Set STATE $=0, \sigma_{\mathrm{u}}=0, \varepsilon_{\mathrm{u}}=0, \varepsilon_{\mathrm{r}}=0$. The state parameter STATE has three different values: 0 indicates loading along the skeleton curves, 1 indicates unloading and reloading along the same curves, and 2 indicates zero stress. In addition, the state parameters $\sigma_{\mathrm{u}}, \varepsilon_{\mathrm{u}}$ and $\varepsilon_{\mathrm{r}}$ are the stress and strain of the unloading point and the strain of the residual point respectively. (2) updating the state parameters based on the strain increment $\mathrm{d} \varepsilon$ from ABAQUS, as shown in Fig.16. (3) calculating the stress according to the current STATE value. 


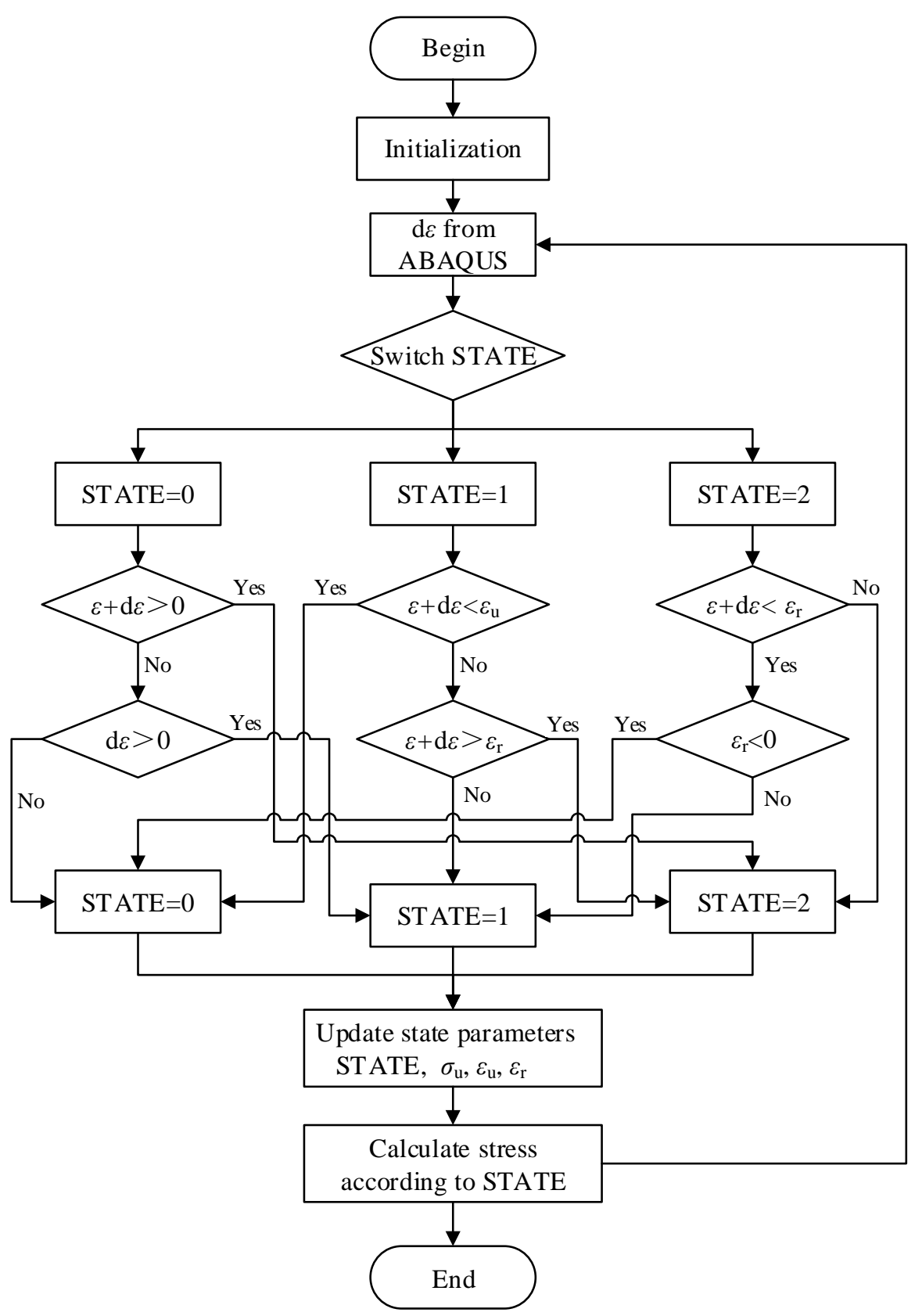

Fig. 15 Flow diagram of the developed UMAT subroutine for the RAC material

\subsection{Validation of the UMAT subroutine}

For validation purpose, a cantilever RAC column under axial loading is analyzed utilizing the developed UMAT subroutine. The cross-sectional dimension of the column is $150 \mathrm{~mm} \times 150 \mathrm{~mm}$ and the height is $300 \mathrm{~mm}$. The parameters $r, f_{\mathrm{c}}^{\mathrm{r}}$ and $\varepsilon_{0}^{\mathrm{r}}$ are set as 50\%, $30 \mathrm{MPa}$ and 0.002 respectively. The column is simulated by one B31 element and axial cyclic displacement is applied at the top, as shown in Fig. 16a. Fig. 16b shows the computed stress-strain relationship extracted from one integral 
point on the column, which agrees well with the constitutive relationship proposed in Section 3.

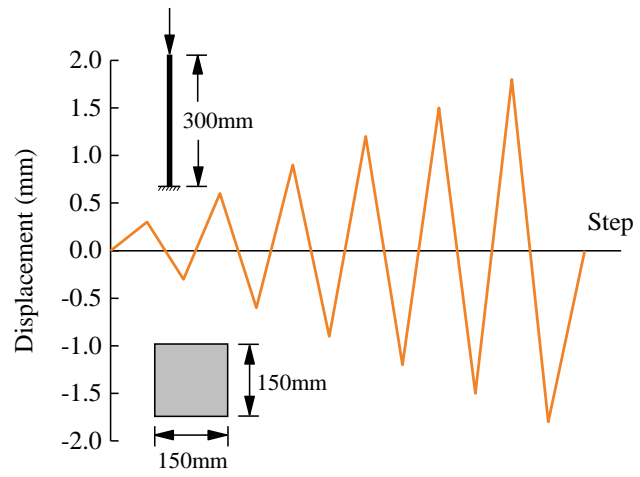

(a) Loading protocol

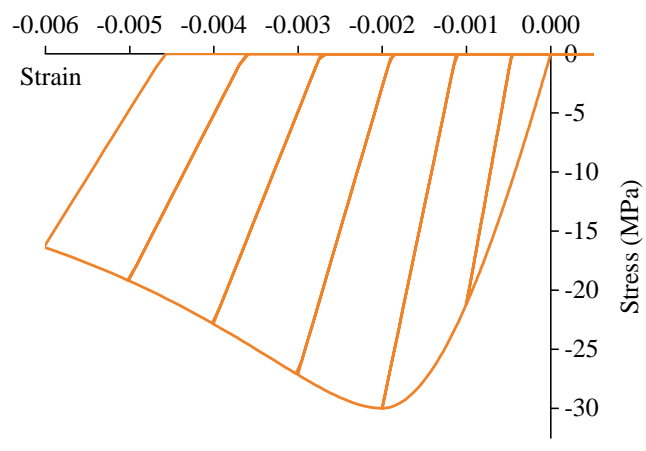

(b) Stress-strain curve

Fig. 16 Analysis of a cantilever RAC column under axial loading

\subsection{Numerical analysis of RAC columns under cyclic loading}

In this section, the developed UMAT subroutine is used to analyze RAC columns under cyclic loading. A total of four RAC column experiments have been adopted [36]. Fig. 17 and Fig. 18 have shown the test configurations of the RAC columns. The key mechanical properties of the columns are summarized in Table 6, where $f_{\mathrm{y}}, E$ and $v$ are the yield strength, elastic modulus and Poisson's ratio of the rebar respectively.

Table 6 Mechanical properties of the selected columns and frames

\begin{tabular}{cccccccc}
\hline \multirow{2}{*}{ Reference } & Specimen & & & & & \\
& No. & $r(\%)$ & $f_{\mathrm{c}}^{\mathrm{r}}(\mathrm{MPa})$ & $N(\mathrm{kN})$ & $f_{\mathrm{y}}(\mathrm{MPa})$ & $E(\mathrm{GPa})$ & $v$ \\
\hline \multirow{2}{*}{ Xiao et al. [36] } & NCCC-1 & 0 & 30.5 & 809 & & & \\
& RCCC-2 & $100 \%$ & 28.4 & 754 & 353 & 196 & 0.3 \\
& RCZ-0 & 0 & 37.2 & 502 & & & \\
Bai et al. [37] & RCZ-100 & $100 \%$ & 33.9 & 458 & & 200 & 0.3 \\
& FRAC-30 & $30 \%$ & 26.1 & - & & & \\
Xiao et al. [38] & FRAC-50 & $50 \%$ & 24.8 & - & 448 & 206 & 0.3 \\
& & & & & & & \\
\hline
\end{tabular}

The columns were modelled using the B31 element. The rebar were modelled by editing the keywords in the ABAQUS input file, and an elastic perfectly-plastic material model was adopted. Note that the effect of stirrups is not taken into account in this analysis. The lateral force-displacement hysteresis curves at the top of the columns are plotted in Fig. 19. Overall, the computed curves agree 
well with the experimental results. Compared to Specimen RCZ-0 and RCZ-100, the hysteresis curves of Specimen NCCC-1 and RCCC-2 exhibit more significant pinching effect due to their smaller slenderness ratios. This phenomenon is well predicted by the simulations. Therefore, it can be drawn that the proposed RAC constitutive model could well capture the hysteresis performance of the RAC on the component level.

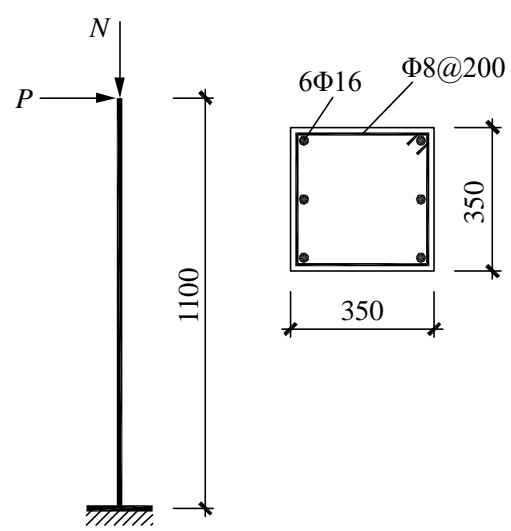

Fig. 17 RAC Columns studied by Xiao et al. [36] (unit: mm)

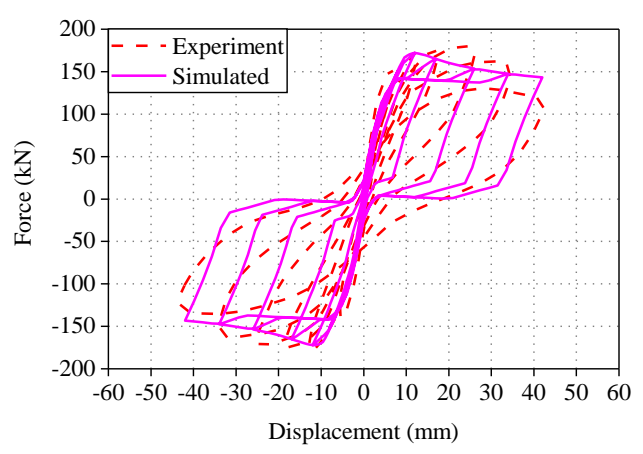

(a) Specimen NCCC-1

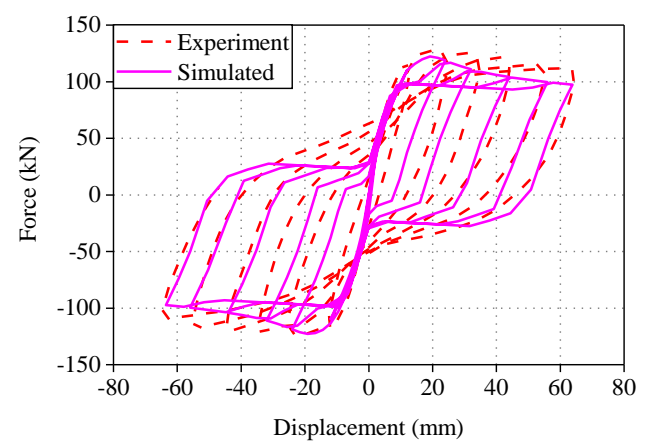

(c) Specimen RCZ-0

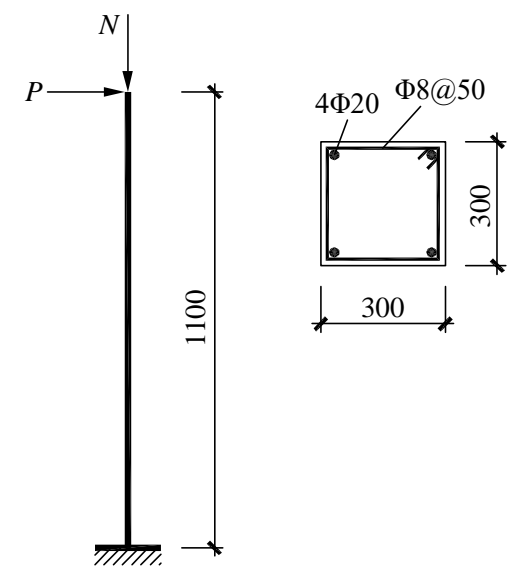

Fig. 18 RAC Columns studied by Bai et al. [37] (unit: $\mathrm{mm}$ )

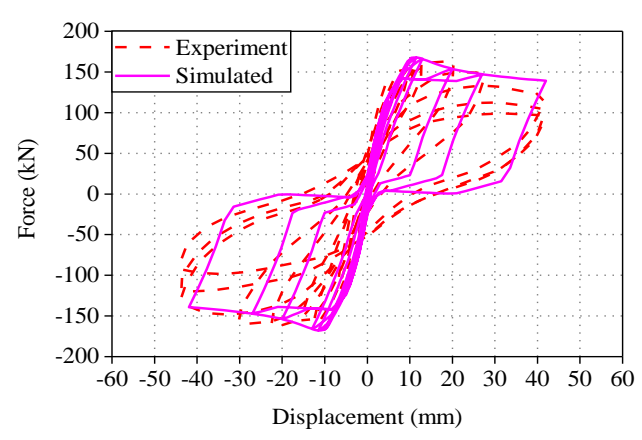

(b) Specimen RCCC-2

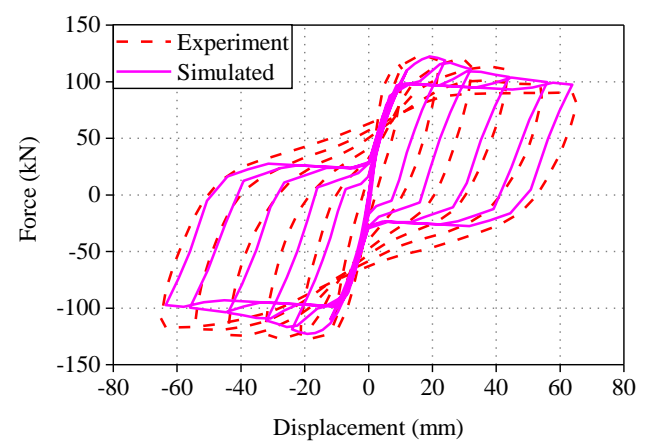

(d) Specimen RCZ-100

Fig. 19 Analysis of the RAC columns under cyclic loading 


\subsection{Numerical analysis of RAC frames under cyclic loading}

The developed UMAT subroutine is further adopted to analyze RAC frames under cyclic loading. A total of two singe-storey and single-bay plane RAC frames (as shown in Fig. 20) under cyclic loading have been adopted [38]. The relevant mechanical properties are also summarized in Table 6.

Fig. 21 compares the numerical and experimental lateral force-displacement hysteresis curves at the top of the frames. It can be seen that the computed skeleton curves agree well with the test results in general. Although the experimental hysteresis curves demonstrated more obvious pinching shapes compared to the simulations, this discrepancy tends to be smaller as the RCA replacement percentage increases. From the above numerical studies, it is concluded that the RAC constitutive model is reliable in capturing the overall hysteresis performance of RAC structures.

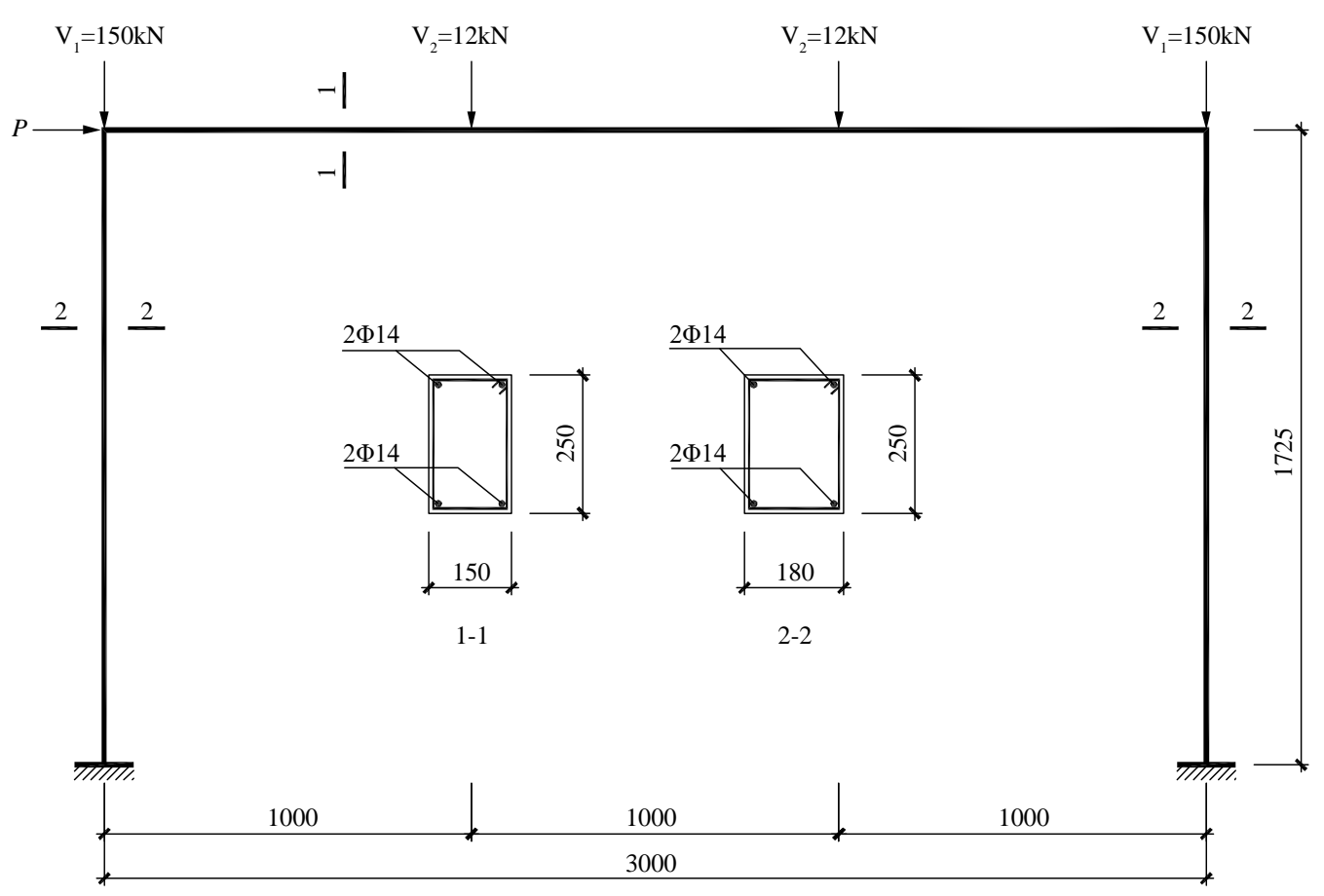

Fig. 20 RAC Frames studied by Xiao et al. [38] (length unit: mm) 


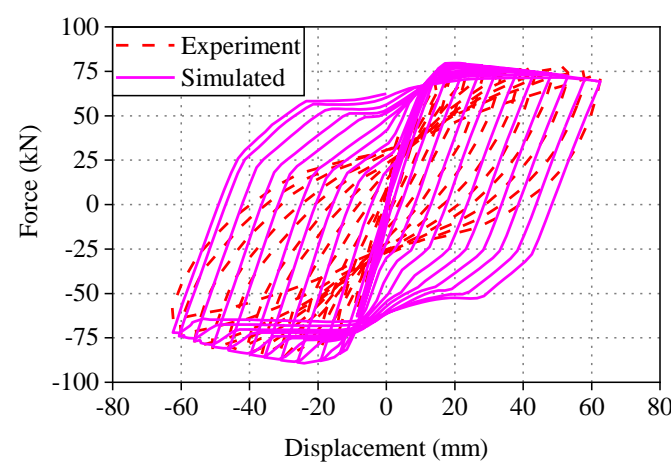

(a) Specimen FRAC-30 $(r=30 \%)$

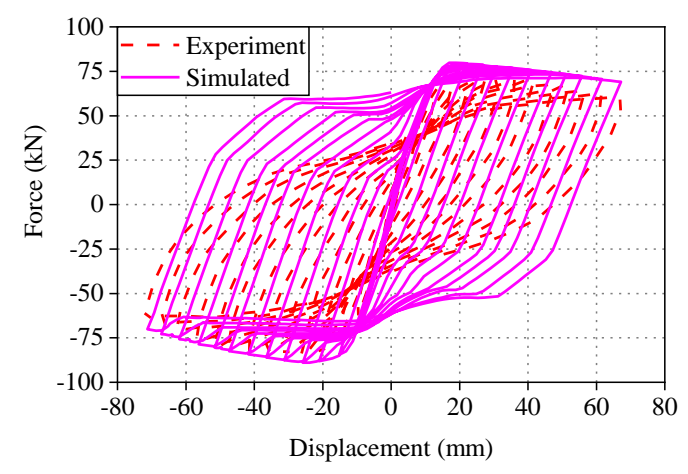

(b) Specimen FRAC-50 $(r=50 \%)$

Fig. 21 Analysis of the RAC frame under cyclic loading

\section{Conclusion}

In this paper, the mechanical behavior of the RAC specimens under cyclic loading as well as monotonic loading was experimentally investigated. The stress-strain curves of the RAC specimens for different RCA replacement ratios were obtained. Based on the test results, a total of four characteristic points corresponding to a typical hysteresis loop were defined and the constitutive equations of the RAC under cyclic loading were proposed. Finally, the proposed simplified constitutive model of RAC is further developed in the software ABAQUS and adopted to analyze the RAC columns and frame structures under cyclic loading. The following conclusions have been drawn:

(1) The RAC and NC specimens demonstrated similar failure characteristics under both monotonic and cyclic loading. However, compared to the NC specimen, more small inclined cracks were developed on the surface of the RAC specimens. Furthermore, the inclination angles of the cracks on the surface of the RAC specimens with respect to the longitudinal axis were larger.

(2) The skeleton curves of the stress-strain relationship of the RAC specimens under cyclic loading have shown similar shapes to the stress-strain curves of the RAC under monotonic loading. However, with the increase of the RCA replacement percentage, the discrepancy tends to be larger.

(3) The proposed constitutive relation of the RAC under cyclic compressive loading has relatively high computational accuracy and can be reliably used to predict the hysteresis performance of the RAC at both component and structural levels.

\section{Acknowledgement}

This paper is part of a project that has received funding from the European Union's Horizon 2020 research and innovation programme under grant agreement $\mathrm{N}^{\circ} 777823$. 


\section{References}

[1] J.Z. Xiao, Recycled Aggregate Concrete, China Architecture \& Building Press, Beijing, 2008.

[2] S. Marinković, V. Radonjanin, M. Malešev, I. Ignjatović, Comparative environmental assessment of natural and recycled aggregate concrete, Waste Management, 30 (11) (2010) 2255-2264.

[3] I.B. Topçu, N.F. Günçan, Using waste concrete as aggregate, Cement and Concrete Research, 25 (7) (1995) 1385-1390.

[4] J. Xiao, J. Li, C. Zhang, Mechanical properties of recycled aggregate concrete under uniaxial loading, Cement and Concrete Research, 35 (6) (2005) 1187-1194.

[5] Z.H. Deng, H.F. Yang, J. Lin, S.H. Wen, Experimental study on the stress-strain curve of recycled concrete, Concrete (11) (2008) 22-24. (in Chinese).

[6] A. Akbarnezhad, K.C.G. Ong, M.H. Zhang, C.T. Tam, T.W.J. Foo, Microwave-assisted beneficiation of recycled concrete aggregates, Construction and Building Materials, 25 (8) (2011) 3469-3479.

[7] I. Martínez-Lage, F. Martínez-Abella, C. Vázquez-Herrero, J.L. Pérez-Ordóñez., Properties of plain concrete made with mixed recycled coarse aggregate, Construction and Building Materials, 37 (2012) 171-176.

[8] G.F. Belén, M.A. Fernando, C.L. Diego, S.P. Sindy, Stress-strain relationship in axial compression for concrete using recycled saturated coarse aggregate, Construction and Building Materials, 25 (5) (2011) 2335-2342.

[9] X. Li, Recycling and reuse of waste concrete in China. Part I. Material behaviour of recycled aggregate concrete, Resources, Conservation and Recycling, 53 (1-2) (2008) 36-44.

[10] C. Zhou, Z. Chen, Mechanical properties of recycled concrete made with different types of coarse aggregate, Construction and Building Materials, 134 (2017) 497-506.

[11] J. Andal, M. Shehata, P. Zacarias, Properties of concrete containing recycled concrete aggregate of preserved quality, Construction and Building Materials, 125 (2016) 842-855.

[12] G. Andreu, E. Miren, Experimental analysis of properties of high performance recycled aggregate concrete, Construction and Building Materials, 52 (2014) 227-235.

[13] M. Breccolotti, A. D'Alessandro, F. Roscini, M.F. Bonfigli, Investigation of stress - strain behaviour of recycled aggregate concrete under cyclic loads, Environmental engineering and management journal, 14 (7) (2015) 1543-1552.

[14] M.C. Limbachiya, Coarse recycled aggregates for use in new concrete, Engineering Sustainability, 157 (2) (2004) 99-106.

[15] S. Laserna, J. Montero, Influence of natural aggregates typology on recycled concrete strength properties, Construction and Building Materials, 115 (2016) 78-86.

[16] W. Wang, L. Zhao, Y. Liu, Z. Li, Mechanical properties and stress-strain relationship in axial compression for concrete with added glazed hollow beads and construction waste, Construction and Building Materials, 71 (2014) 425-434.

[17] M. Rühl, G. Atkinson, The influence of recycled aggregate concrete on the stress-strain relation of concrete, Darmstadt Concrete, 14 (1999).

[18] M. Etxeberria, E. Vázquez, A. Marí, M. Barra, Influence of amount of recycled coarse aggregates and production process on properties of recycled aggregate concrete, Cement and Concrete Research, 37 (5) (2007) 735-742.

[19] S. Manzi, C. Mazzotti, M.C. Bignozzi, Short and long-term behavior of structural concrete with recycled concrete aggregate, Cement and Concrete Composites, 37 (1) (2013) 312-318.

[20] Z.H. Deng, L. Chen, J. Qian, C.L. Meng, Experimental Study on Stress-Strain Curve of Recycled Coarse 
Aggregate Concrete under Uniaxial Compression, Applied Mechanics and Materials, 357-360 (2013) 1415-1419.

[21] N.Y. Ho, Y.P.K. Lee, W.F. Lim, T. Zayed, K.C. Chew, G.L. Low, S.K. Ting, Efficient Utilization of Recycled Concrete Aggregate in Structural Concrete, Journal of Materials in Civil Engineering, 25 (3) (2013) 318-327.

[22] Á. Salesa, J.A. Pérez-Benedicto, D. Colorado-Aranguren, P.L. López-Julián, L.M. Esteban, L.J. Sanz-Baldúz, J.L. Sáez-Hostaled, J. Ramis, D. Olivares, Physico - mechanical properties of multi recycled concrete from precast concrete industry, Journal of Cleaner Production, 141 (2017) 248-255.

[23] N.K. Bairagi, K. Ravande, V.K. Pareek, Behaviour of concrete with different proportions of natural and recycled aggregates, Resources, Conservation and Recycling, 9 (1-2) (1993) 109-126.

[24] T. Du, W. Wang, Z. Liu, H. Lin, T. Guo, The complete stress-strain curve of recycled aggregate concrete under uniaxial compression loading, Journal Wuhan University of Technology, Materials Science Edition, 25 (5) (2010) 862-865.

[25] H. Yang, Z. Deng, Y. Huang, Analysis of Stress - Strain Curve on Recycled Aggregate Concrete under Uniaxial and Conventional Triaxial Compression, Advances in Building Materials, 168-170 (2011) 900-905.

[26] J.A. Carneiro, P.R.L. Lima, M.B. Leite, R.D. Toledo Filho, Compressive stress-strain behavior of steel fiber reinforced-recycled aggregate concrete, Cement and Concrete Composites, 46 (2014) 65-72.

[27] C. Wang, J. Xiao, Evaluation of the stress-strain behavior of confined recycled aggregate concrete under monotonic dynamic loadings, Cement and Concrete Composites, 87 (2018) 149-163.

[28] Ministry of construction of the People's Republic of China, JGJ52-2006 Standard for technical requirements and test method of sand and crushed stone (or gravel) for ordinary concrete, China Architecture \& Building Press, Beijing, 2006.

[29] Ministry of construction of the People's Republic of China, Standard for test method of mechanical properties on ordinary concrete, China Architecture \& Building Press, Beijing, 2003.

[30] C. Shi, Y. Li, J. Zhang, W. Li, L. Chong, Z. Xie, Performance enhancement of recycled concrete aggregate - A review, Journal of Cleaner Production, 112 (2016) 466-472.

[31] M. Etxeberria, E. Vázquez, Microstructure analysis of hardened recycled aggregate concrete, Materiales de Construccion, 60 (297) (2006) 47-58.

[32] Z.H. Guo, Strength and Deformation of Concrete: Experimental basis and Constitutive Relations, Tsinghua University Press, Beijing, 1997.

[33] S.H. Xu, A.B. Li, H.P. Cui, X.W. Liu, Experimental investigation of the stress-strain response of carbonated concrete under repeated loading, Journal of Harbin Institute of Technology, 47 (12) (2015) 57-63. (in Chinese).

[34] S. Mazzoni, F. Mckenna, M.H. Scott, G.L. Fenves, Open system for earthquake engineering simulation, user command-language manual, Pacific Earthquake Engineering Research Center, Berkeley, California, 2006.

[35] Dassault Systèmes, Abaqus user subroutines reference guide, RI, USA, 2013, available at http://dsk.ippt.pan.pl/docs/abaqus/v6.13/books/sub/default.htm.

[36] J.Z. Xiao, X. Huang, L.M. Shen, Seismic behavior of semi-precast column with recycled aggregate concrete, Construction and Building Materials, 35 (2012) 988-1001.

[37] G.L. Bai, C. Liu, H.J. Zhao, F. Yao, L.H. Zhu, Experimental research on seismic behavior of recycled concrete frame columns, Journal of Earthquake Engineering and Engineering Vibration, 31 (1) (2011) 61-66. (in Chinese). 
[38] J.Z. Xiao, Y.D. Sun, H. Falkner, Seismic performance of frame structures with recycled aggregate concrete, Engineering Structures, 28 (1) (2006) 1-8. 